\title{
Academic Library Statistics Revisited
}

\begin{abstract}
Claims are made that the latest (Library Statistics of Colleges and Universities, 1965-66: Institutional Data) report on national academic library statistics contains "great" and "frequent" errors. Numerous examples are given. Excessive use of individual reports which are rendered almost useless by qualifying footnotes and disregard of what was asked for is noted. Since these national figures are used for many significant purposes (such as replies to Congressional inquiries), it is urged that ACRL once more take up the task of compiling them.
\end{abstract}

I

N November 1964 CRL published an $\operatorname{article}^{1}$ concerning academic library statistics which was intended as a one-time study of "certain imperfections and misleading inclusions and omissions that deserve some attention and analysis." The recent publication of Library Statistics of Colleges and Universities, 196566: Institutional Data compels a return to what were, in 1964, believed to be strictures which would not need repeating as soon as three years later-particularly in light of the aegis under which this newest study was issued, as "Compiled by the Library Administration Division of the American Library Association."

It appears, however, that whether the federal government or the American Library Association prepares college and university statistics, the pitfalls of these publications are so great and likely errors so frequent that the profession might be better off without any so-called "national" cumulation of figures at all. No lengthy research is necessary to support this point.

The earlier article particularly em-

${ }^{1}$ Eli M. Oboler, "The Accuracy of Federal Academic Library Statistics," College and Research Libraries XXV (November 1964), 494-97.

Mr. Oboler is University Librarian of Idaho State University, Pocatello. phasized the "rather odd figures" given for "volumes" and for "volumes added," especially in relation to expenditures indicated for "books and other library materials." If 1962-63 was considered "rather odd" in this report, then 1965-66 was, to say the least, weird.

Item: a library with 59,000 volumes at the end of 1963-64 reports holding well over 100,000 volumes as of July 1,1966 , despite adding only a few more than 2,500 volumes during 1965-66. This would, of course, mean that during 196465 this same library had to have added about 40,000 volumes!

Item: another academic library, with somewhat more than 90,000 volumes as of 1963-64, records nearly 184,000 as of 1965-66.

Item: a third, with slightly more than 350,000 volumes in 1963-64 and "volumes added" that year of a little more than 19,000 suddenly becomes "big-time," with nearly 550,000 volumes in 1965-66, despite the fact that they indicate fewer than 35,000 volumes added in the same year. One must assume that this institution had around 515,000 in 1964-65 having added the prodigious figure of 160,000 (almost 50 per cent!) during the year.

Or do these, and many similar comparative figures, reflect not errors in reporting, but rather (what could be inter- 
esting) the fact that since 1963-64 there have been substantial changes in the definition of a volume. An examination of definitions, however, indicate that there has been no such change. For 1963-64 a volume is defined ${ }^{2}$ as "A physical unit of any printed, typewritten, handwritten, mimeographed or processed work contained in one binding or portfolio, hardbound or paperbound, which has been classified, cataloged, or otherwise prepared for use. The term includes bound periodical volumes and all non-periodical government documents. All forms of microtext are excluded."

In the 1967 report is found ${ }^{3}$ the following definition: "Volume. A physical unit of any printed, typewritten, handwritten, mimeographed or processed work contained in one binding or portfolio, or otherwise prepared for use. The term includes bound periodicals [sic] volumes and all non-periodical government documents. All forms of microtext are excluded." This does not look like a very substantial change. Actually, the only difference between the two definitions is the omission of the words “. . . hardbound or paperbound, which has been classified, cataloged...." Thus, there seems to be no evidence of justification for "errors" by change in definition of the disputed term "volume."

Can such variations in reporting be explained in another way? In a preface to the 1967 volume, Theodore Samore says: ${ }^{4}$ "The substantial number of incompleted forms necessitated the application of valid editing procedures to retrieve data which would have otherwise been unavailable. Hence, the considerable increase in the number of foot-

${ }^{2}$ U.S. Office of Education, Library Statistics of Colleges and Universities, 1963-64 Institutional Data. OE-15023-64. Circular No. 769. (Wash., D.C.: U.S. G.P.O., 1965), p. 4.

3 ALA Library Administration Division, comp. Library Statistics of Colleges and Universities, 1965-66 Institutional Data (Chicago: ALA, 1967), p. 3.

+ Ibid., p. 2. notes, especially those marked 'estimate." "Since the matter of "estimated" figures is supposedly taken care of by Mr. Samore's explanation, let us look over the actual use of "estimated" figures.

As was pointed out in the 1964 article, the use of rounded-off figures is a fairly clear indication of the use of estimation, rather than actual physical or bibliographical count to determine results. The 1965-66 records show use of "estimated" as a footnote (on the matter of volume count) twenty-three times; yet thirty-five other academic institutions show " 000 " at the end of their volume figures, without stating that their figures are estimated.

The figures for "number of volumes added during year" present a similar picture. Of the 1,891 institutions which gave "volumes added" figures, only six footnoted their figures as "estimated," yet fifty-eight other college and university libraries used rounded-off figures.

Despite the explicit instructions in the questionnaire which was the basis of this report, no fewer than nine did include some type of microtext as part of the figures reported under "number of volumes at end of year," of whom three included microtexts added under "number of volumes added during year." Although of all government document holdings only non-periodical government documents were to be counted as volumes in this survey, one university library "excludes unbound government documents," one college library "excludes US and UN documents," and one university library "excludes non-periodical government documents." Surely these figures should have been omitted, rather than being counted with an explanatory footnote added, if the totals based on them are supposed to be reliable guides to current trends or situations in academic library resources.

The data concerning microtext holdings in this report are also interesting. 
The questionnaire gave this definition of microform: $:^{5}$ "Microform. This includes the form of any library material which has been photographically reduced in size for storage and reproduction purposes, and which must be read with the help of enlarging instruments. The term is synonymous with microtext and includes microfilm, microcard, and microfiche." Column 10 of Table 1 of the 1965-66 report calls for "number of physical units of microform at end of year." Of the respondents, forty-one gave "estimated" figures; three gave "bibliographical count only" (although physical units were specifically asked for); one gave "volume count only"; one gave "microfilm only" (which probably means that their microform holdings of documents and manuscripts were not reported, but one cannot be sure). And, finally, on this matter, one indicated that it had so many physical units of microform, and so many volumes, but footnoted "data for microform included . . . volumes." It might be asked why this library did not simply subtract one figure from the other and report that total as was asked for, or why the editor did not do it for them?

One must admire the candor of one small church-supported college which reported, "All figures are estimates." Included were such data as the total number of students, the size of the library, the total budget, the number of staff, and even the beginning salary of a library school graduate (fifth year degree without experience). Somehow, however, the mind boggles at any academic librarian "estimating" how many students are registered in his institution or how many individuals are on the library staff.

The earlier study of statistics referred to the "wonderland of academic statistics," and said ${ }^{6}$ that "the further one goes .... the 'curioser and curiouser'

${ }^{5}$ ALA, op. cit., p. 3.

Oboler, op. cit., p. 494. they get." What has been printed in the 1967 report leads one to repeat the comment. When one correlates replies printed under "number of volumes added during year" with the amounts reported as expenditures for "books and other library materials," one runs upon an additional number of unusual figures.

Taking up Table 2, "Operating Expenditures, Personnel, and Beginning Salary ..." one finds some intriguing footnotes. Under "Wages," for example, twenty-eight give "estimated" figures, four state that their reports exclude "funds from Federal Work-Study Program," six say "student assistants only," and one indicates his figures "include all employees paid on an hourly basis." How this latter differs from other reports on "Wages" ( since the questionnaire said, "Amounts (including monetary estimates for contributed services) paid to students and to others paid on an hourly basis are listed under 'wages," " is difficult to understand.

One of the more unusual presentations in Table 2 comes up where total operating expenditures in dollars are asked for. One institution lists a particular specific amount under "total" and then footnotes it as "estimated." Yet none of the other figures for this institution-salaries, cost of library material, binding, or "other" -are marked "estimated." The total of the four figures given is about 3 per cent above the total given as "estimated!"

Surely the above examples of irresponsible and confused reporting bear out the charges at the beginning of this article. If further evidence is required, one need only look at Table $\mathrm{B}^{7}$ in the 1965-66 report. The figures for the total number of volumes at the end of the year for the academic library reporting say, most ingenuously "(includes microtext)." Yet the questionnaires on which this table is based exclude all forms of 
microtext in asking for "number of volumes at end of year," "number of volumes added during year," and "number of volumes withdrawn during year."

The same Table B is footnoted to indicate that all figures for 1966 (that is to say, 1965-66) are "estimated." The previous comments in this article on the values of estimation should be noted again, especially when one realizes that official statements on the state of American academic libraries now are usually based on this olla podrida of invalid and unreliable statistics. The figures given for "number of periodicals received" are footnoted. "For 1965-66, the figures are for Serials which includes periodicals, annuals, proceedings, transactions, etc."
Then why even give 1965-66 figures, since they are based on such hollow shells of fact as are indicated throughout this article, obviously incapable of any meaningful comparison with past data?

In sum, the statistics picture for academic libraries in the United States is at least cloudy, if not psychedelic. Perhaps the task should be returned to the Association of College and Research Libraries, which seemed to do a pretty fair job for a great many years, before the computers, the federal government, and the Library Administration Division took over.

In at least one man's judgment, bad - even misleading-statistics are worse than no statistics at all.

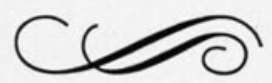

